Archives of Agriculture and Environmental Science

\title{
Species Selection Index (SSI): A novel tool designed for bio-resource selection under Access and Benefit Sharing (ABS) mechanism
}

\author{
Salman Khan ${ }^{1^{*}}$ (D) , Sohom Seal ${ }^{1}$, Swanti Sharma ${ }^{2}$ and Upasana Joshi ${ }^{3}$ \\ ${ }^{1}$ Forest Entomology Division, Forest Research Institute Dehradun-248006 (Uttarakhand), INDIA \\ ${ }^{2}$ School of Environment \& Natural Resources, Doon University, Dehradun-248001 (Uttarakhand), INDIA \\ ${ }^{3}$ Centre for Business Entrepreneurial and Development, Vasant Vihar, Dehradun-248006, (Uttarakhand), INDIA \\ *Corresponding author's E-mail: salman1315@gmail.com
}

\section{ARTICLE HISTORY}

Received: 08 April 2019

Revised received: 08 May 2019

Accepted: 21 May 2019

\section{Keywords}

Access and Benefit Sharing

Biodiversity

Bio-resources

Species Selection Index (SSI)

\section{ABSTRACT}

This investigation was designed for the use of species selection index (SSI) for bio-resource selection under access and benefit sharing mechanism. The bio-resources are being utilized by different industries for manufacturing various end products. Uttarakhand is known for its bio-resources having highly medicinal properties. But, these bio-resources are on the verge of extinction because of over-exploitation. These bio-resources are not being utilized in a sustainable manner. Access and Benefit-sharing is the mechanism by which a species would benefit both producer and traders apart from the conservation. Selection of the concerned species from the area to be considered for ABS mechanism is a tedious work. In this paper, an attempt has been made to solve this issue. The objective was to formulate a methodology for the selection of native species for ABS. A novel method (Species Selection Index) has been formulated for this purpose. Study was conducted at organization, industry and village level. Different species from Uttarkashi, Pauri and Haridwar of Uttarakhand has been analysed by this method and compared with each other. Positive and Negative criteria were considered for the selection and based on the result Terminalia chebula and Zanthoxylem armatum was suggested for ABS. Therefore, The SSI can be used in the selection of any bio-resources to be considered for ABS mechanism or for any other developmental project. More SSI value means more suitable species to be considered for project related activity.

(C)2019 Agriculture and Environmental Science Academy

Citation of this article: Khan, S., Seal, S., Sharma, S. and Joshi, U. (2019). Species Selection Index (SSI): A novel tool designed for bio-resource selection under Access and Benefit Sharing (ABS) mechanism. Archives of Agriculture and Environmental Science, 4(2): 163-170, https://dx.doi.org/10.26832/24566632.2019.040206

\section{INTRODUCTION}

Biodiversity does not confine to the species of forest area only but it also includes biodiversity of Agriculture, Horticulture, Fisheries, grasslands and others. India is named among the 17 mega-diversity countries of the world having $2.4 \%$ of the world's land area, supporting $7 \%$ of globally recorded species including 45,000 plants and 91,000 animal species (ABSPP, 2017). The Ministry of Environment and Forest implemented the Conference of Parties decision of CBD and made the induction of Biological Diversity Act. The Biological Diversity Act, 2002 and Rules, 2004 was formulated by National Biodiversity of India u/s 8 (Venkataraman, 2008) to facilitate ABS (Prathapan and Rajan,
2011). Tully (2003) provided the detailed on technical and practical elements added by the Bonn Guidelines in Article 15 of the CBD. The biodiversity of different biological resources are being declined day by day, especially in the Himalayan region. The Himalayan region accounts for the good diversity of flora and fauna including medicinally important species (Khera et al., 2001). So far about 8000 species of angiosperms, 44 species of gymnosperms and 600 species of pteridophytes have been reported in the Indian Himalaya (Singh and Hajra, 1996). The reason for the decline of such bio-resources could be both natural and anthropogenic factor. The natural factors are also directly related to the anthropogenic activities. The diversity of plants in an area is related to site attributes and human impacts 
and varies accordingly (Parthasarathy and Karthikeyan, 1997). The anthropogenic activities are inversely related to the biodiversity of an area (Spangenberg, 2007). The loss of any bio-resource is also due to the unsustainable use or overexploitation of such bio-resource. As per the ASI (1994) around 4635 tribal communities are based on 7500 plant species in India. The local community is primarily based on medicinal plants of the nearby areas for the healthcare (Shankar and Majumdar, 1997; Venkataraman, 2008) as part of their Traditional Knowledge (TKs). The TKs associated with any village community are the Indigenous knowledge of that community. Though, the Indigenous peoples and local communities have an important role in the conservation and management of the local biodiversity (Mauro and Hardison, 2000). Based on such traditional knowledge associated with the bio-resource, different herbal industries are now established throughout India. Use of the traditional knowledge of any community for business purpose is being regulated by the government of India but its main aim is to conserve the right of the forest dwellers or local communities to which the TKs belongs. The uses of concerned bio-resources for manufacturing different end products are increasing every year (Kuniyal et al., 2013). As demand for medicinal plants is increasing, the supply cannot be maintained due to the unavailability of the concerned bio-resources. The industrial demand for any bioresource is too high and thus it requires to feed lots of quintals of the bio-resource but the major source of obtaining those bioresources are forest only. As forest has natural ecological environment balanced in its own way naturally (Thuiller, 2007). No one can rely on the collection of the bio-resources from the forest because it is being maintained by the forest department of the concerned range or division. But still, the industries are able to get some amount of bio-resources from the forest where it is available, legally or illegally. These results, stress on the forest biodiversity and species extinction started. Bioprospecting is somewhat similar to this as exploration of commercial genetic resource (Moran, 2000). Also, due to unavailability of such bioresources many industries were shut down. So, plantation of such bio-resources over an area is the alternative of the forestbased collections. But to ensure that the bio-resources are being supplied on a continuous basis in a sustainable manner, the concept of Access and Benefit Sharing (ABS) came into existence after Nagoya Protocol (Anuradha,2000). ABS agreements govern the access to these bio-resources and sharing of the benefits arising from their use between involved parties (Cock et al., 2010). ABS benefits are recognized as non-monetary as no royalty has been extracted from such agreement in many countries including Brazil (Davalos et al., 2003). In Uttarakhand, around 107 industries have applied for the ABS for different bio-resources (UKSBB, 2017a). Also, First ABS Agreement signed between Uttarakhand Biodiversity Board and Habib Cosmetic Pvt. Ltd. (UKSBB, 2017b). ABS requires support from a wide range of stakeholders, such as government organizations, Non-Governmental Organizations (NGOs), Industries, local villagers (Siebenhüner and Suplie 2005). The selection of the bio-resources for which the ABS has to be formulated are being selected on the basis of certain criteria. (1) The first criterion is that it should not be a species of concern i.e., Rare, Endangered or Threatened. (2) The species selected should not be exotic. (3) and the species should not be on the list of Not Traded Commodity as decided by National Biodiversity Authority, Government of India (NBA, 2017). The present work is on the selection of bio-resources for ABS mechanism based on different criteria.

\section{MATERIALS AND METHODS}

The study was conducted in Uttarkashi, Pauri and Haridwar district of Uttarakhand, India with the geographical area as $8016 \mathrm{~km}^{2}$ (Census 2011a), $5329 \mathrm{~km}^{2}$ (Census 2011b) and $2360 \mathrm{~km}^{2}$ (Census 2011c) respectively. A survey was conducted in the month of September-October, 2017 in all the three districts. At preliminary level, the literature survey was conducted with NFLIC (National Forest Library and Information Centre, Dehradun) and CBED (Centre for Business Entrepreneurial and Development, Dehradun). Various research organisations were also visited for the collection of secondary data related to the study area. Government departments and NGOs were also considered for the data collection. The forest divisions of all the three districts were visited for identification of the bio-resources available in the area and the working plan was also consulted. The study was conducted at three different level: Industry level, Organization level (Government/NGOs/Research) and Village level (Figure 1). The method followed for the study, at all the three-level included questionnaire-based survey and personal interviews (Sharma et al., 2016). At industries level, basic information about procurement of raw materials to the manufacturing of the final product. Management policies at the different level of operations were also discussed with the officials of the concerned industry. Questions related to forest-based bio-resources, the collection procedure, quantity, demand and supply mechanism, sharing of royalty or ABS information (if present), other associated cost, bi-products and its management and R\&D related information were also asked during the meetings with industrial staffs. Based on such interactions, villages from where the raw materials (bioresources) are procured were selected. Similarly, the study at government level was conducted using the methodology followed for industries. The management plan, conservation strategies, the scientific approach adopted (if any) were discussed. Also, the working plan was reviewed for the collection of information on floral and faunal diversity. Jila Bheshaj Sangh (JBS) and UFDC (Uttarakhand Forest Development Corporation) at each district were visited for survey and data collections. Survey at village level was conducted using Participatory Rural Appraisal (PRA), Questionnaires and personal interviews. The BMC (Biodiversity Management Committee), Self Help Groups (SHGs), Mahila Mangal Dal (MMD) and Yuva Mangal Dal (YMD) were the target audience for the data collection at the village level. The data collected was further analysed by SPSS (16.0). The Boston Consulting Group (BCG) matrix was also analysed for the selection of the species under ABS mechanism. 


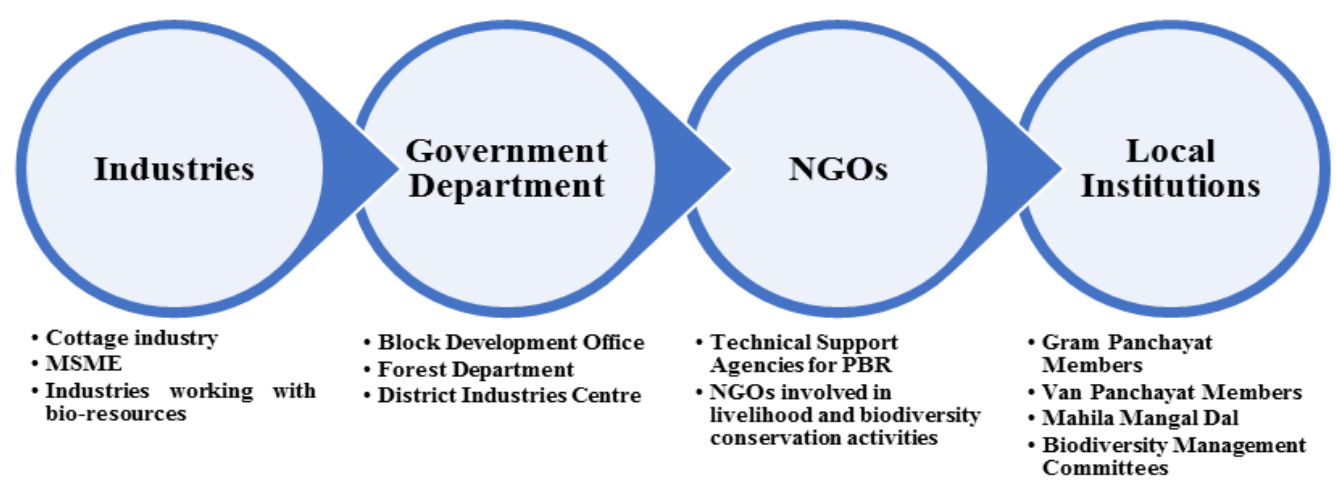

Figure 1. Different level of study for data collection.

\section{RESULTS AND DISCUSSION}

Based upon the questionnaires, the results obtained was categorised on the basis of six criteria namely, Availability, Price, Market availabilities, Traditional knowledge and diversified uses, Industrial demand, labour cost, Time-bound, Accessibility, Collateral damage to regeneration, Storage issues. The mentioned characters are divided into two categories, Positive and Negative criteria. Description of the Species Selection Index (SSI) is as follows:

\section{Positive criteria}

Positive criteria of Species Selection Index (SSI) are related to the direct or indirect effect of any criterion on bio-resource. These criterions are based upon the questionnaires survey conducted in the study areas (Table 1). Higher the index value of any criteria signifies the suitability of the concerned bio-resource for ABS.

\section{Availability}

The availability of any bio-resources is one of the positive criteria under SSI. The availability of any bio-resources in an area is termed as Availability in this context. Any bio-resources is said to be available in an area only if it is distributed throughout. Also, the concerned species should be in available in adequate quantity. This criterion is measured on the scale of 1 to 5 in positive quantity. The scale value of 1 denotes that the concerned bio-resource or species are very less available; 2 means the availability is less. Similarly, 3 and 4 values, denote medium and high availability of the bio-resource. The value 5 denotes very high availability of any bio-resource (Table 1).

\section{Price}

The price of any bio-resources is the market rate at which, it can be sold. If the market rate of any specific bio-resource is very high then we would assign it 5 as its index value. Similarly, if any species or bio-resource has a very low rate in the market then we would assign its index value as 1 . In the case of bio-resource whose market rate is neither too high and nor too low then such species would be treated with index value as 3 (Table 1).

\section{Market availabilities}

Market availabilities are directly related to the bio-resource trade. If any specific bio-resource, available in the area is widely demanded by the different stakeholders (Traders). It is basically criterion of market demand and relative availability of the market. Any bio-resources consider for ABS should have the proper market to be sold. So, if the market is poorly available then the index value of that bio-resource would be 1 and if it has very high market demand then it would be assigned the index value of 5 . The scenarios of any species in between index value of 1 and 5 would be considered for index value as 3 (Table 1).

Traditional knowledge and diversified uses

Traditional knowledge (TKs) is the indigenous knowledge of any community associated with any bio-resource. It includes the various beliefs, faith, traditions and uses of any bio-resource in their religious or cultural activities. Diversified uses include the uses of any bio-resource other than its general uses. It could be the TKs of any community. The index value of 5 denotes that the concerned species have very wide range of uses in the different communities. If any specific species has not much-diversified use or TKs then it would have given the index value as 1 (Table 1).

\section{Industrial demand}

The industrial demand is also one of the criteria in SSI as the demand is a very important factor. Industrial demand is the demand of any important bio-resource by the industries for manufacturing various end products. If the demand for any species would be high at the industrial level then the species would be more prioritize for cultivation among the local community. So, this way the species would be regenerated throughout the area. The value index of 1 and 5 denotes the very low and very high demand of any bio-resource by different industries (Table 1).

\section{Negative criteria}

Negative criteria of Species Selection Index (SSI) are related to the direct or indirect effect of any criterion on bio-resource. The index values of these criterions are taken in negatives (-ve) as they are the considered as a constraint in the bio-resources uses (Table 2). Less negative, the index value of any criteria signifies the more chance of selection of the concerned bio-resource for ABS.

\section{Labour cost}

Labour cost is considered as one of the major factors for the selection of any bio-resource. The extraction of some of the bioresources can only be possible by employing the labours. From 
Table 1. Mechanism of crediting the positive criteria according to their degree.

\begin{tabular}{|c|c|c|}
\hline Criteria & Range & Index \\
\hline \multirow{5}{*}{$\begin{array}{l}\text { Availability: Frequency of the targeted species is } \\
\text { calculated. (Phillips 1959) }\end{array}$} & Frequency $>80 \%$ & 5 \\
\hline & Frequency $=60-80 \%$ & 4 \\
\hline & Frequency $=40-60 \%$ & 3 \\
\hline & Frequency $=25-40 \%$ & 2 \\
\hline & Frequency $<25 \%$ & 1 \\
\hline \multirow{5}{*}{$\begin{array}{l}\text { Price: Price at which the bio-resource is available to the } \\
\text { primary consumers. }\end{array}$} & Price $>$ Rs. 400/kg & 5 \\
\hline & Price $=$ Rs. $200-400 / \mathrm{kg}$ & 4 \\
\hline & Price $=$ Rs. $100-200 / \mathrm{kg}$ & 3 \\
\hline & Price $=$ Rs. $50-100 / \mathrm{kg}$ & 2 \\
\hline & Price < Rs. 50/kg & 1 \\
\hline \multirow{5}{*}{$\begin{array}{l}\text { Market availabilities: The distance from the point of } \\
\text { collection to the nearest market available. }\end{array}$} & Distance $<5 \mathrm{~km}$ & 5 \\
\hline & Distance $=5-10 \mathrm{~km}$ & 4 \\
\hline & Distance $=10-20 \mathrm{~km}$ & 3 \\
\hline & Distance $=20-40 \mathrm{~km}$ & 2 \\
\hline & Distance $>40 \mathrm{~km}$ & 1 \\
\hline \multirow{5}{*}{$\begin{array}{l}\text { Traditional knowledge and diversified uses: No. of } \\
\text { different traditional knowledge associated to the targeted } \\
\text { species. }\end{array}$} & Traditional knowledge and uses $>=4$ & 5 \\
\hline & Traditional knowledge and uses $=3$ & 4 \\
\hline & Traditional knowledge and uses $=2$ & 3 \\
\hline & Traditional knowledge and uses $=1$ & 2 \\
\hline & No Traditional knowledge & 1 \\
\hline \multirow{5}{*}{$\begin{array}{l}\text { Industrial demand: Percentage of bio-resource being sold } \\
\text { from the Mandis to the industries. }\end{array}$} & $100 \%$ sold & 5 \\
\hline & $70-100 \%$ sold & 4 \\
\hline & $50-70 \%$ sold & 3 \\
\hline & $30-50 \%$ sold & 2 \\
\hline & $<30 \%$ sold & 1 \\
\hline
\end{tabular}

extraction to the final product, labour is required for the various purpose. The cost of extraction of any bio-resource is related to the availability of that species. The index for labour cost varied from -1 to -5 of which -1 denotes very low labour cost, while very high labour cost was denoted by -5 for concerned bio-resource (Table 2).

\section{Time-bound}

The time bound is a very important factor while selecting the bio -resource for ABS mechanism. Time-bound is meant to be the availability of any bio-resource in the year. Few species are available 3 months in a year and few available throughout the year. So, the availability duration of any bio-resource in a year was taken as one of the factors for determining the SSI. If any species is available throughout the year, has been recommended -1 as its index value. Similarly, the index value of -5 denotes very seasonally (3 months or less) (Table 2 ).

\section{Accessibility}

Accessibility of any bio-resources to be collected from an area is also considered as one of the important factors in determining the SSI. Some species are available at higher altitudes or unreachable places. So, if one not able to harvest such bio-resources cannot be considered for ABS mechanism. If the harvesting of such bio-resources is very difficult, then the index value assigned would be -5 . Also, if the same is easy then the index value given would be -1 (Table 2).

\section{Collateral damage to regeneration}

While collecting or harvesting the bio-resources, there is some negative impact on other plant individuals, considered under the collateral damage to regeneration. During the extraction of cer- tain bio-resource regeneration get uprooted, collapsed or damaged and also, the seed get disturbed during its regeneration period. So, the collateral damage to regeneration is related to the type of bio-resource being extracted. If the extraction of any bio-resource has a large adverse impact on the other crops being regenerated then the index value assigned would be -5 and if no collateral damage occurs to regeneration then the index value assigned would be -1 (Table 2).

\section{Storage issues}

The storage-related issue includes the problems faced during the storage of any bio-resource. Any bio-resource can be stored, either for short duration or long duration. The fruits of some bio -resources contain a high amount of water, which tends to have the low storage properties. If any species found to have long duration storage properties was given its index value as -1 and if the storage is not possible for much time, have been assigned its index value as -5 (Table 2 ).

\section{Case studies of Species Selection Index (SSI)}

The information collected about the bio-resources from the three districts Haridwar, Uttarkashi and Pauri were analysed using SSI. Not all the species were taken into consideration but for the purpose of example, 10 bio-resources were selected. SSI is the advanced form of Force Field analysis (Thomas, 1985). The index value assigned to each character is given in Table 3. The Aegle marmelos is being used as important medicinal plant against the abdominal related disorders. The positive criteria, "Availability" for the A. marmelos was assigned with index value of 4 because throughout the selected district (Frequency 60$80 \%$ ), the species was found available. Also, the "Price" and "Market availabilities" are assigned with an index value of 3 and 
Table 2. Mechanism to credit the negative criteria according to their degree.

\begin{tabular}{|c|c|c|}
\hline Criteria & Range & Index \\
\hline \multirow[t]{5}{*}{$\begin{array}{l}\text { Labour cost: Labour Cost associated with individual species is calculated per } \\
\mathrm{kg} \text { of extraction. }\end{array}$} & Highest extreme value & -5 \\
\hline & $>$ than median value but $<$ Highest extreme value & -4 \\
\hline & Median Value & -3 \\
\hline & $>$ than median value but $<$ Highest extreme value & -2 \\
\hline & Lowest extreme value & -1 \\
\hline \multirow{5}{*}{ Time-bound: No. of months the specific bio-resource is available in a year. } & $<4$ months & -5 \\
\hline & 4 months & -4 \\
\hline & 6 months & -3 \\
\hline & 9 months & -2 \\
\hline & $>9$ months & -1 \\
\hline \multirow[t]{5}{*}{$\begin{array}{l}\text { Accessibility: Time for extraction of } 1 \mathrm{~kg} \text { of the targeted bio-resource is } \\
\text { calculated. }\end{array}$} & 1 kg. extracted @ > $>8$ hours & -5 \\
\hline & 1 kg. extracted @ $<2$ hours & -4 \\
\hline & 1 kg. extracted@4-6hours & -3 \\
\hline & 1 kg. extracted@6-8 hours & -2 \\
\hline & 1 kg. extracted @2-4 hours & -1 \\
\hline \multirow{5}{*}{$\begin{array}{l}\text { Collateral damage to regeneration: A } 1 \times 1 \text { quadrat is laid at the spot of extrac- } \\
\text { tion and the damage to regeneration crops are calculated. }\end{array}$} & Death of regenerating plant $>10$ & -5 \\
\hline & Death of regenerating plant $=8-10$ & -4 \\
\hline & Death of regenerating plant $=6-8$ & -3 \\
\hline & Death of regenerating plant $=4-6$ & -2 \\
\hline & Death of regenerating plant $<4$ & -1 \\
\hline \multirow[t]{5}{*}{ Storage issues: Only air-drying storage mechanism is considered. } & No. of days stored $>15$ days & -5 \\
\hline & No. of days stored $=10-15$ days & -4 \\
\hline & No. of days stored $=7-10$ days & -3 \\
\hline & No. of days stored $=3-7$ days & -2 \\
\hline & No. of days stored $<3$ days & -1 \\
\hline
\end{tabular}

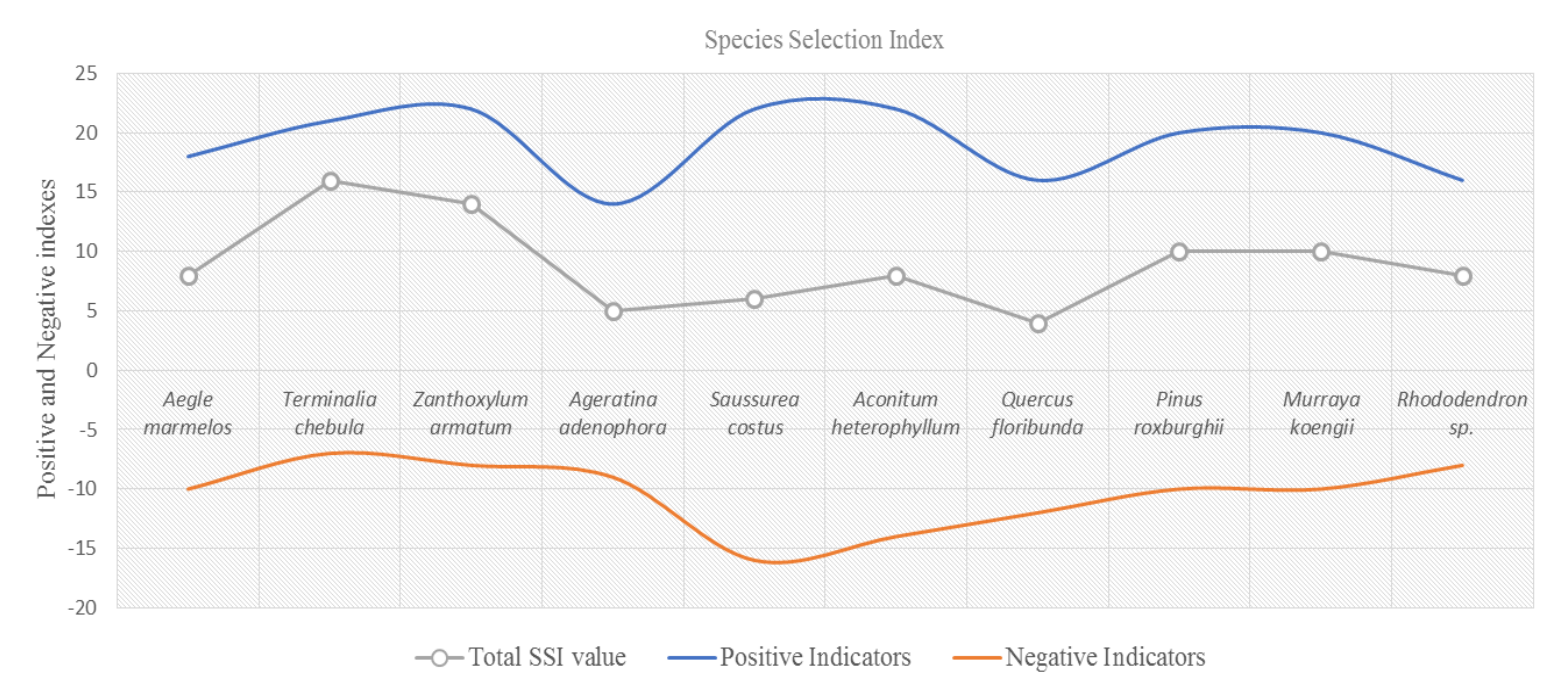

Figure 2. Total SSI index and indexes of positive and negative criteria of the bio-resources from Uttarakhand.

4 respectively. The price for $A$. marmelos is neither too costly and nor too cheap (100-150/kg). Similarly, the market availability of the A. marmelos is in relatively good conditions (with $5-10 \mathrm{~km}$ of harvesting). The A. marmelos has the much traditional knowledge and diversified uses apart from the general use so the index value is 4. The Industrial demand for A. marmelos is also up to the mark (more than $50 \%$ of the stock sold) due to its highly medicinal property and thus the index value assigned is 3 . The negative criteria such as "Labour cost" is also not too much for the extraction of $A$. marmelos and is being available only at the certain time frame of the year (April-July) so "Labour cost" and "Time-bound" were assigned with an index value of -1 and -4 , respectively. The "Accessibility" of the A. marmelos is also very easy and approachable. The "Collateral damage to regeneration" was also not much during the A. marmelos extraction (<4 plants/sampling unit). So, both "Collateral damage to regeneration" and "Accessibility" were assigned with an index value of -1 . The A. marmelos has certain storage issue because of its pulpiness. The water in A. marmelos tends to make the $A$. marmelos more prone to attack by the various microorganisms. So, due to some moderate storage issue (can be stored for 7-10 days), it has been assigned the index value of -3 . The index value of positive criteria was found highest for Saussurea costus, Aconitum heterophyllum and Zanthoxylum armatum due to the high price, market and traditional uses. Similarly, the index value for negative criteria was found the minimum for $S$. costus. Also, Terminalia chebula was observed with minimum index value in negative criteria suggest it almost equal to positive criteria (Figure 2). 


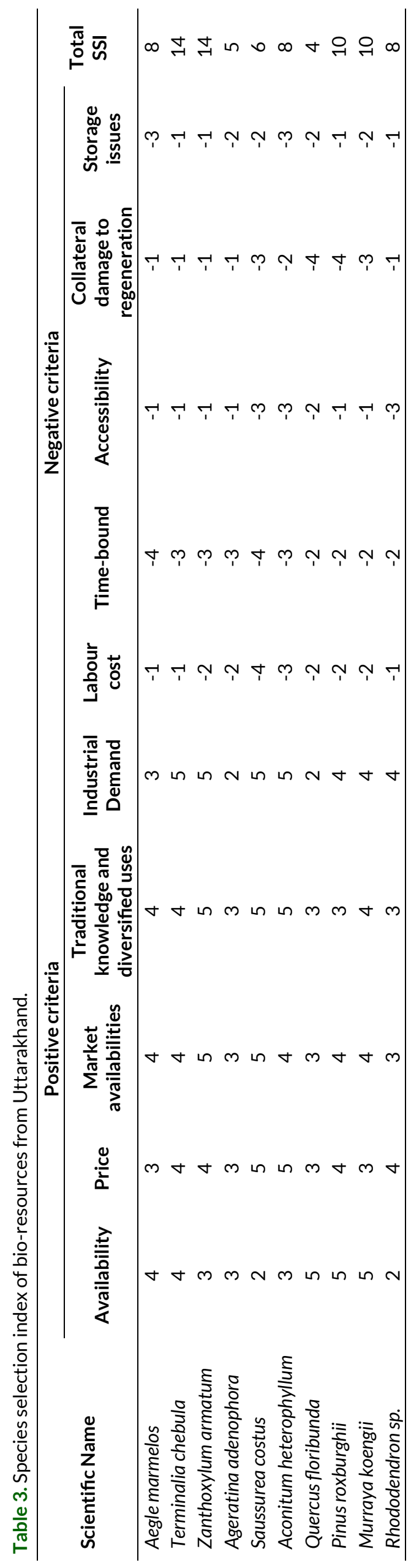

S. costus and Rhododendron sp. were given lowest index value in "Availability" (Table 3). As in Rhododendron sp. the flower cannot take place in sexual reproduction and next generation hardly regenerate. It is because of the plucking of the Rhododendron flower for squash preparation. The maximum index value of Quercus floribunda and Pinus roxburghii (index value 5). The price was found highest (index value 5) for S. costus and A. heterphyllum. The low price (index value 3) was found in A. marmelos, Ageratina adenophora, Q. floribunda and Murraya koengii due to the large production. The market availability of $Z$. armatum and S. costus was indexed as 5 because they can be sold in the very nearby market (less than $5 \mathrm{~km}$ ). Other species with the index value as 3 can be sold easily but the market is not nearby and they have to travel to a particular place or mandi to sell the produces.

The Traditional knowledge and diversified uses of Z. armatum, S. costus and $A$. heterphyllum were found highest and so given the index value as 5 whereas, A. adenophora, Q. floribunda, Pinus roxburghii and Rhododendron sp. was an index with the lowest value as 3 in comparison to other species. The industrial demand of the T. chebula, Z. armatum, Saussurea costus and A. heterophyllum was found highest and so assigned by the index value of 5 . The A. adenophora and Q. floribunda were measured as the lowest index (2) due to the less demand by the industries. In the case of negative criteria, the labour cost was noted minimum in A. marmelos, T. chebula and Rhododendron sp. whereas the maximum cost was observed for $S$. costus.

A. marmelos and S. costus are very timely bound and available for less than 4 months. The accessibility was found the maximum $(-1)$ in almost all the species except S. costus, A. heterophyllum, Q. floribunda and Rhododendron sp. which means that the abovementioned species are very hard to collect. The collateral damage to the regeneration was minimum $(-1)$ in $A$. marmelos, $T$. chebula, Z. armatum, A. adenophora and Rhododendron sp. but the maximum collateral damage was observed in the case of Quercus floribunda and Pinus roxburghii (index value as -4 ) and thus the regeneration of other species including Q. leucotrichophora get affected because of extraction. The storage capability of $A$. marmelos and $A$. heterophyllum was observed highest as they can be stored for 7-10 days only. So, they are assigned with an index value of -3 . In case of T. chebula, Z. armatum, P. roxburghii and Rhododendron sp., the storage capacity was found good.

Finally, the species which receives maximum total SSI value should be selected for the ABS mechanism as a potential species to be considered for trade in a sustainable manner. So, T. chebula and Z. armatum are recommended for ABS potential species as they receive the highest SSI value of 14 (Table 3). Similarly, $P$. roxburghii and $M$. koengii was found with SSI value as 10 which is quite low, but in comparison to other species, they have good values of criteria. So, if we could supplement the positive criteria and control the negative criteria by making policies and plans then these two species can also be considered for ABS. The minimum SSI was observed in Q. floribunda (4) which means that this particular species should not be considered for any type of trade. The biodiversity of Uttarakhand should be conserved in the proper way by utilizing the bio-resources in a sustainable manner. 


\section{Conclusion}

One of the requirements for Access and Benefit Sharing of resources/medicinal plants is its availability. Other factors of concern are price, market and storage etc. All these factors could be looked upon by a single methodology that is the Species Selection Index (SSI). This is a method in which useful criterions are selected, given weightage and based on highest weightage species are selected. In the present study also, the methodology helped in identification of ten medicinal plant species in Uttarakhand which could be used for access and benefit sharing. There could be some positive factor or criteria which can enhance the chances of any species to be considered for trade. These criteria on broad sense are Availability (assessed by measuring the frequency of the individual bio-resource), Price (the rate of concerned bio-resources, available to the primary consumer), Market availability (availability of the nearby market to sell the concerned bio-resource), Traditional knowledge and diversified uses (the use of any bio-resources other than the principal/general use) and Industrial demand (assessed by the bio-resources being able to sold). Similarly, there is some negative criteria also which leads to the rejection of any bio-resource to be considered for trade under ABS mechanism. The negative criteria were accessed in broad way as Labour cost (the cost of extraction of any bio-resource/kg), Time-bound (the time of availability of any bio-resources in a year), Accessibility (accessed by taking the time of extraction of each kilogram of the concerned bio-resource), Collateral damage to regeneration (the damage caused to other regeneration while collection of the specific bio-resource) and Storage issue (No. of days the concerned bio-resource can be stored for use). These positive and negative criteria were added together on the basis of index value given to each character (based upon the bio-resources characteristics) and combined index value formed. These combined index value is termed as Species Selection Index (SSI). The SSI can be used in the selection of any bio-resources to be considered for ABS mechanism or for any other developmental project. More SSI value means more suitable species to be considered for project related activity.

\section{ACKNOWLEDGEMENT}

This research was carried out in the framework of the project 'Bio-resource assessment and value chain analysis of abs potential species/products in selected districts of Garhwal region, Uttarakhand' (Contract no. 83261418 July, 2017) funded by Indo-German Biodiversity Program, Deutsche Gesellschaft fur Internationale Zusammenarbeit (GIZ) $\mathrm{GmbH}$, India.

Open Access: This is an open access article distributed under the terms of the Creative Commons Attribution 4.0 License, which permits unrestricted use, distribution, and reproduction in any medium, provided the original author(s) if the sources are credited.

\section{REFERENCES}

ABSPP. (2017). Indo-German Biodiversity Programme. Retrieved on 15 November, 2017 from http://www.indo-germanbiodiversity.com/pdf/project/ ABS_BROCHURE_2017.pdf

Anuradha, R.V. (2000). Sharing the benefits of biodiversity the Kani TBGRI deals in Kerala, India. Journal of International Wildlife Law \& Policy, 3(2): 125-151.

ASI. (1994). People of India Project Report for 1994. Anthropological Survey of India.

Census (2011a). Uttarkashi district: Census 2011-2019 data. Retrieved on 21 November, 2017 from http://www.census2011.co.in/census/district/574uttarkashi.html

Census (2011b). Pauri district: Census 2011-2019 data. Retrieved on 21 November, 2017 from http://www.census2011.co.in/census/district/579-paurigarhwal.html

Census (2011c). Haridwar district: Census 2011-2019 data. Retrieved on 21 November, 2017 from http://www.census2011.co.in/census/district/586haridwar.html

Cock, M.J., van Lenteren, J.C., Brodeur, J., Barratt, B.I., Bigler, F., Bolckmans, K., Cônsoli, F.L., Haas, F., Mason, P.G. and Parra, J.R.P. (2010). Do new access and benefit sharing procedures under the convention on biological diversity threaten the future of biological control? BioControl, 55(2): 199-218.

Davalos, L.M., Sears, R.R., Rygorodetsky, G., Simmons, B.L., Grant, T., Barnes, T., Putzel, L. and Porzecanski, A.L. (2003). Regulating access to genetic resources under the convention on Biological Diversity: an analysis of selected case studies. Biodiversity and Conservation, 12(7): 1511-1524.

Khera, N., Kumar, A., Ram, J. and Tewari, A. (2001). Plant biodiversity assessment in relation to disturbances in mid-elevational forest of Central Himalaya, India. Tropical Ecology, 42(1): 83-95.

Kuniyal, C.P., Kuniyal, P.C., Butola, J.S. and Sundriyal, R.C. (2013). Trends in the marketing of some important medicinal plants in Uttarakhand, India. International Journal of Biodiversity Science, Ecosystem Services \& Management, 9(4): 324-329.

Mauro, F. and Hardison, P.D. (2000). Traditional knowledge of indigenous and local communities: international debate and policy initiatives. Ecological Applications, 10(5): 1263-1269.

Moran, K. (2000). Bioprospecting: lessons from benefit-sharing experiences. International Journal of Biotechnology, 2(1-3): 132-144.

NBA (2017). National Biodiversity Authority. Retrieved on 21 November, 2017 from http://nbaindia.org/uploaded/pdf/ Notification_of_Normally_Tradeded_Commidities_dt_7_April_2016.pdf

Parthasarathy, N. and Karthikeyan, R. (1997). Plant biodiversity inventory and conservation of two tropical dry evergreen forests on the Coromandel coast, south India. Biodiversity and Conservation, 6(8): 1063-1083.

Phillips, E.A. (1959). Methods of Vegetation study. In: Henry Holt. \& Co., Inc. New York.

Prathapan, K.D. and Rajan, P.D. (2011). Biodiversity access and benefit-sharing: weaving a rope of sand. Current Science, 100(3): 290-293.

Shankar, D. and Majumdar, B. (1997). Beyond the biodiversity convention: the challenges facing the biocultural heritage of India's medicinal plants. Medicinal Plants for Forest Conservation and Health Care, 11: 87-99.

Sharma, G., Partap, U., Sharma, E., Rasul, G. and Awasthe, R.K. (2016). Agrobiodiversity in the Sikkim Himalaya: Sociocultural Significance, Status, Practices, and Challenges. ICIMOD Working paper 2016/2 Kathmandu: ICIMOD. Retrieved on 21 November, 2017 from http://lib.icimod.org/ record/32307/files/WP\%202016_5\%20Agrobiodiversity\%20in\%20the\% 20Sikkim.pdf

Siebenhüner, B. and Suplie, J. (2005). Implementing the access and benefit-sharing provisions of the $\mathrm{CBD}$ : A case for institutional learning. Ecological Economics, 53(4): 507-522.

Singh, D.K. and Hajra, P.K. (1996). Floristic diversity. Changing perspective of biodiversity status in the Himalaya. British Council Division, 23-38.

Spangenberg, J.H. (2007). Integrated scenarios for assessing biodiversity risks. Sustainable Development, 15(6): 343-356.

Thomas, J. (1985). Force field analysis: A new way to evaluate your strategy. Long Range Planning, 18(6): 54-59.

Thuiller, W. (2007). Biodiversity: climate change and the ecologist. Nature Reports Climate Change, 60-62.

Tully, S. (2003). The Bonn guidelines on Access to Genetic Resource and Benefit Sharing. Reciel, 12(1): 84-98. 
UKSBB (2017a). Uttarakhand Biodiversity Board. Retrieved on 17 November, 2017 from http://www.sbb.uk.gov.in/files/ABS/Status_of_compliance11.pdf UKSBB (2017b). Uttarakhand Biodiversity Board. Retrieved on 17 November, 2017 from http://www.sbb.uk.gov.in/files/act/abs_agreement.pdf
Venkataraman, K. (2008). Access and Benefit Sharing and the Biological Diversity Act of India: A progress Report. Asian Biotechnology and Development Review, 10(3): 69-80. 